\title{
Mechanisms and Modeling Approaches of Radon Emanation for Natural Materials
}

\author{
Akihiro SAKODA*1,\# and Yuu ISHIMORI*1,†
}

(Received on October 20, 2017)

(Accepted on November 16, 2017)

\begin{abstract}
Radon emanation means the escape of radon atoms from solid grains into pore space; it is the very first process that may lead to radon exposure in the environment. Experimental and numerical studies of radon emanation have been diligently carried out since its recognition as a carcinogen. Our previous review of the measured data showed a wide range of radon emanation fractions from natural substances, and then we discussed the effects of environmental factors such as pore water. The present paper provides an overview of the approaches and progress of radon emanation modeling that may be useful for the interpretation of measured data. Recoil and/or diffusion of radon in solid following alpha decay of radium, which underlies the mechanisms of radon emanation, have been incorporated into numerical models. In the calculation based on recoil-based emanation, radium distribution and pore size were the most important parameters, which govern the magnitudes of radon ejections from the birth grain and of radon embedding into another solid surface, respectively. The solid diffusion appeared significant only at a temperature higher than several hundred degrees Celsius. A model is now desired to be developed that incorporates the transport process of radon atoms that are still settled in solid after alpha recoil, considering radiation damage and its resulting inner path network.
\end{abstract}

KEY WORDS: radon emanation, modeling, alpha recoil, solid diffusion, grain, pore, environmental factors.

\section{INTRODUCTION}

Before radon, a radioactive inert gas, migrates through soil and disperses in the atmosphere, it must first escape from radium-bearing solid grains. Escape of radon atoms from grains into pore space is called as emanation, which should be distinguished from exhalation characterized by the emanation of radon and subsequent migration through pore fluid. A number of radon emanation measurements have been carried out from the viewpoint of health physics as well as geoscience, because emanation is the very first process in context of radon exposure.

Of radon isotopes, ${ }^{222} \mathrm{Rn}$ and ${ }^{220} \mathrm{Rn}$ are dominant in the environment. Rn-222 with a half-life of 3.8 days, formed by the alpha decay of ${ }^{226} \mathrm{Ra}$ belonging to uranium series, has been of great concern in several decades from the aspect of radiation protection. Recently, interest has also been growing in ${ }^{220} \mathrm{Rn}$ with a half-life of $56 \mathrm{~s}$, as a decay product of ${ }^{224} \mathrm{Ra}$ in thorium series. Uranium, thorium, and radium are ubiquitous

*1 Ningyo-toge Environmental Engineering Center, Japan Atomic Energy Agency; 1550 Kamisaibara, Tomata-gun, Kagamino-cho, Okayama 708-0698, Japan.

Corresponding author; E-mail: sakoda.akihiro@jaea.go.jp

Present address: Prototype Fast Breeder Reactor Monju, Sector of Fast Reactor Research and Development, Japan Atomic Energy Agency; 2-1 Shiraki, Tsuruga-shi, Fukui 919-1279, Japan. elements in natural materials such as rock and soil, implying that radon is always produced in them. A fraction of radon atoms generated in such materials has a possibility to be emanated into inter- or intra-particle pores. Table 1 indicates the representative values of radon emanation fractions for mineral, rock, soil, mill tailing, and fly-ash samples. ${ }^{1,2)}$ The radon emanation fraction is defined as the number of radon atoms emanated per number of radon atoms generated; other terms such as emanation coefficient and emanating power have also been used alternatively. This fraction must be in the range $0-1$. Among mineral, rock, and soil samples, mineral and soil generally tend to have the lowest and highest radon emanation fractions, respectively, which could be explained

Table 1 Representative radon emanation fractions for various materials.

\begin{tabular}{ccc}
\hline \multirow{2}{*}{ Material } & \multicolumn{2}{c}{ Emanation fraction $(-)$} \\
\cline { 2 - 3 } & ${ }^{222} \mathrm{Rn}^{1)}$ & ${ }^{220} \mathrm{Rn}^{2)}$ \\
\hline Mineral & 0.03 & 0.01 \\
Rock & 0.13 & 0.11 \\
Soil & 0.20 & 0.14 \\
Mill tailing & 0.17 & $\mathrm{NA}$ \\
Fly ash & 0.03 & $\mathrm{NA}$ \\
\hline
\end{tabular}

Note: All emanation tests were not necessarily performed under the same environmental conditions. 
by the different solid structures because of the formation and weathering processes. However, even based on the current knowledge, it is often difficult to predict how or understand why a given sample exhibits large or small radon emanation.

Many experimental and numerical studies have been carried out to facilitate the understanding of radon emanation phenomenon. A few reviews summarized measured data, ${ }^{1,3,4)}$ but no reviews overviewed numerical modeling studies (except for one Japanese article, which was dedicated only to specific topics of recoil-based emanation ${ }^{5}$ ). The present paper reviews the mechanisms and modeling approaches and progress of radon emanation as well as discusses environmental factors affecting radon emanation with typical calculated data. Note that, in this paper, the term radon refers to ${ }^{222} \mathrm{Rn}$ and ${ }^{220} \mathrm{Rn}$ and radium refers to ${ }^{226} \mathrm{Ra}$ and ${ }^{224} \mathrm{Ra}$.

\section{MECHANISMS OF RADON EMANATION}

Figure 1 shows the main pathways of radon emanation. Possible driving forces for emanation are recoil because of the alpha decay of radium and subsequent diffusion in solid. This diffusion process should be considered, only if alpha recoil allowed radon atoms to be settled not in pore air/water but in grains (points (C), (D), (E), (F), and (I) in Fig. 1). For the detection in an emanation test, radon in point $(\mathrm{H})$ would be necessary to move to inter-particle space. Generally, the radon emanation fraction, $E(-)$, can be classified into two or three components: ${ }^{4)}$

$$
E=E_{\text {Recoil }}+E_{\text {Diffusion }}=E_{\text {Direct }}+E_{\text {Indirect }}+E_{\text {Diffusion }},
$$

where $E_{\text {Direct }}$ is the direct-recoil fraction (points (A), (B), (G), and $(\mathrm{H})$ in Fig. 1), $E_{\text {Indirect }}$ is the indirect-recoil fraction (point (E)), $E_{\text {Diffusion }}$ is the solid-diffusion fraction (point (F)), and $E_{\text {Recoil }}$ is the sum of $E_{\text {Direct }}$ and $E_{\text {Indirect }}$.

\section{Alpha recoil}

The transformation of ${ }^{226} \mathrm{Ra}$ or ${ }^{224} \mathrm{Ra}$ by alpha decay creates certain energy, which can be assigned to an alpha particle and its decay product. Subsequently, the decay product (i.e., ${ }^{222} \mathrm{Rn}$ or ${ }^{220} \mathrm{Rn}$ ) can recoil, and thereby be emitted in the opposite direction to the alpha particle. The energy imparted to radon, as exhibited in Table 2, ${ }^{6}$ can contribute to emanation. This table also indicates the ranges of recoiling radon in materials, calculated by SRIM-2013.7) Only a recoil energy of $86.26 \mathrm{keV}$ for ${ }^{222} \mathrm{Rn}$ or $103.4 \mathrm{keV}$ for ${ }^{220} \mathrm{Rn}$ has been used in previous emanation modeling studies, because of high intensity. Even

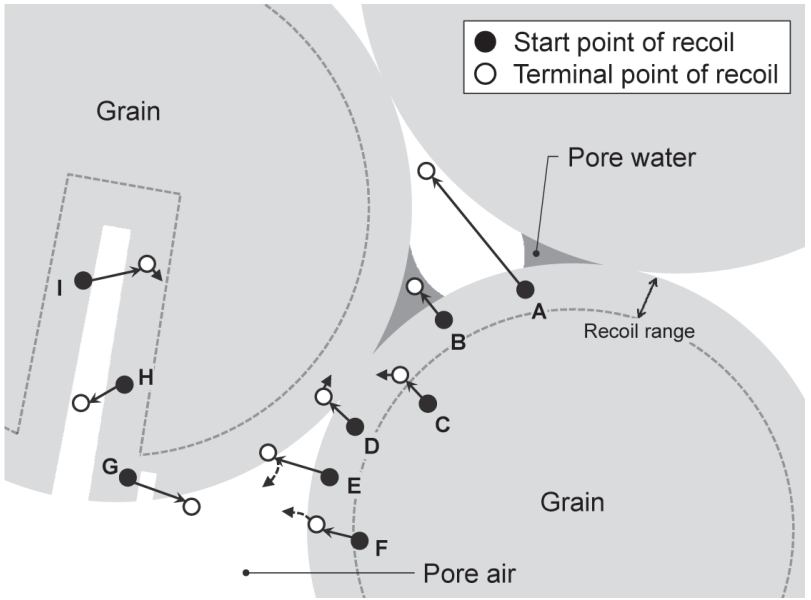

Fig. 1 Scheme of radon emanation phenomenon. Radon atoms in points (A), (B), (E), (F), (G), and (H) are regarded as being emanated and in points (C), (D), and (I) as not emanated. Radon in point $(\mathrm{H})$ is emanated to the intraparticle pore but would be necessary to move to interparticle space for detection. The arrow following the terminal point of recoil represents the diffusion in solid. All arrows are not to scale.

if other energy levels of $82.96 \mathrm{keV}$ for ${ }^{222} \mathrm{Rn}$ or $99.13 \mathrm{keV}$ for ${ }^{220} \mathrm{Rn}$ have been considered for the calculation, the results would barely change.

Alpha recoil not only is specific to the decay of radium isotopes but also accompanies the decay of any alpha emitter. For example, successive alpha recoils in uranium and thorium series have been investigated to argue formations of radiation damage and inhomogeneous distributions of members belonging to those series in minerals. ${ }^{8-10)}$

\section{Solid diffusion}

Diffusion of radon in solid at room temperature has been thought to make no contribution to emanation $\left(E_{\text {Diffusion }}=0\right)$ because of substantially low diffusion coefficients of radon (Table 3). ${ }^{2,4,11-18)}$ The diffusion length, $L(\mathrm{~m})$, is expressed as $L=\sqrt{\frac{D}{\lambda}}$, where $D$ is the diffusion coefficient $\left(\mathrm{m}^{2} \mathrm{~s}^{-1}\right)$ and $\lambda$ is the decay constant $\left(\mathrm{s}^{-1}\right)$. A diffusion coefficient of $10^{-24} \mathrm{~m}^{2} \mathrm{~s}^{-1}$ corresponds to a diffusion length of $0.7 \mathrm{~nm}$ for ${ }^{222} \mathrm{Rn}$ and $9 \times$

Table 2 Kinetic energies assigned to alpha-recoiling radon atoms and their ranges in materials.

\begin{tabular}{ccccccc}
\hline & & \multicolumn{2}{c}{${ }^{222} \mathrm{Rn}$} & & \multicolumn{2}{c}{${ }^{220} \mathrm{Rn}$} \\
\cline { 3 - 4 } \cline { 6 - 7 } Material & Density $\left(\mathrm{g} \mathrm{cm}^{-3}\right)$ & $82.96 \mathrm{keV}$ & $86.26 \mathrm{keV}$ & & $99.13 \mathrm{keV}$ & $103.4 \mathrm{keV}$ \\
& & $(5.55 \%)$ & $(94.4 \%)$ & & $(5.06 \%)$ & $(94.9 \%)$ \\
\hline Air & $1.205 \times 10^{-3}$ & $68.0 \pm 10.3 \mu \mathrm{m}$ & $69.7 \pm 10.5 \mu \mathrm{m}$ & & $75.8 \pm 11.3 \mu \mathrm{m}$ & $77.9 \pm 11.5 \mu \mathrm{m}$ \\
Water & 1 & $73.9 \pm 10.5 \mathrm{~nm}$ & $75.7 \pm 10.7 \mathrm{~nm}$ & & $82.3 \pm 11.4 \mathrm{~nm}$ & $84.5 \pm 11.7 \mathrm{~nm}$ \\
Quartz & 2.65 & $33.1 \pm 6.1 \mathrm{~nm}$ & $33.9 \pm 6.2 \mathrm{~nm}$ & & $36.9 \pm 6.7 \mathrm{~nm}$ & $37.9 \pm 6.9 \mathrm{~nm}$ \\
Zircon & 4.65 & $22.5 \pm 6.1 \mathrm{~nm}$ & $23.0 \pm 6.2 \mathrm{~nm}$ & & $25.0 \pm 6.7 \mathrm{~nm}$ & $25.7 \pm 6.9 \mathrm{~nm}$ \\
\hline
\end{tabular}

Note: The projected recoil ranges and the longitudinal straggling (standard deviation) were calculated by SRIM-2013. ${ }^{7)}$ Values of energy and intensity in parentheses were taken from ICRP Publ. 107.) 
Table 3 Estimated diffusion coefficients of radon and corresponding diffusion lengths in solids at ambient temperature.

\begin{tabular}{|c|c|c|c|c|}
\hline \multirow{2}{*}{ Solid } & \multirow{2}{*}{$D\left(\mathrm{~m}^{2} \mathrm{~s}^{-1}\right)$} & \multicolumn{2}{|c|}{$L(\mathrm{~m})$} & \multirow{2}{*}{ Reference } \\
\hline & & ${ }^{222} \mathrm{Rn}$ & ${ }^{220} \mathrm{Rn}$ & \\
\hline General ionic crystal & $\leq 10^{-24}$ & $\leq 7 \times 10^{-10}$ & $\leq 9 \times 10^{-12}$ & TANNER $(1980)^{4)}$ \\
\hline Mineral & $10^{-25}-10^{-69}$ & $2 \times\left(10^{-10}-10^{-32}\right)$ & $3 \times\left(10^{-12}-10^{-34}\right)$ & LEACH et al. (1982) ${ }^{11)}$ \\
\hline Witherite $\left(\mathrm{BaCO}_{3}\right)$ & $1.6 \times 10^{-22}$ & $8.7 \times 10^{-9}$ & $1.1 \times 10^{-10}$ & FLÜGGE and ZIMENS (1939) ${ }^{12)}$ \\
\hline Potassium feldspar ${ }^{\mathrm{a}}$ & $\approx 10^{-31}$ & $\approx 10^{-13}$ & $\approx 10^{-15}$ & TOKUMORI et al. (1992) ${ }^{13)}$ \\
\hline Zircon $\left(\mathrm{ZrSiO}_{4}\right)^{\mathrm{a}}$ & $\approx 10^{-46}$ & $\approx 10^{-20}$ & $\approx 10^{-22}$ & EAKIN et al. $(2016)^{14)}$ \\
\hline Coal fly ash & $(1.05-9.17) \times 10^{-21}$ & $(2.24-6.61) \times 10^{-8}$ & $(2.90-8.58) \times 10^{-10}$ & $\begin{array}{l}\text { MARAZIOTIS }(1996),{ }^{15,16)} \text { BARTON and } \\
\text { ZIEMER }(1986),{ }^{17)} \text { KALKWARF et al. }(1985){ }^{18)}\end{array}$ \\
\hline \multicolumn{5}{|l|}{ For reference } \\
\hline Air & $1 \times 10^{-5}$ & 2 & $3 \times 10^{-2}$ & $\operatorname{IAEA}(2013)^{2)}$ \\
\hline Water & $1 \times 10^{-9}$ & $2 \times 10^{-2}$ & $3 \times 10^{-4}$ & $\operatorname{IAEA}(2013)^{2)}$ \\
\hline
\end{tabular}

${ }^{a}$ Re-evaluated by the present authors, with extrapolation from high temperature to $20^{\circ} \mathrm{C}$ (see Fig. 2).

$10^{-3} \mathrm{~nm}$ for ${ }^{220} \mathrm{Rn}$. Short distances, as seen in Table 3, can lead us to a conclusion that in natural conditions, $E_{\text {Diffusion }}$ is negligibly smaller than $E_{\text {Recoil }}$ in Eq. (1).

However, the situation is different when the temperature is above several hundred degrees Celsius. The diffusivity is temperature-dependent in nature; $E_{\text {Diffusion }}$ can be enhanced with increasing temperature. BAXTER ${ }^{19)}$ listed enormous data on diffusion coefficients of noble gases (especially helium and argon) in minerals, but no data were reported on radon. Figure 2 shows the dependence of $D$ on temperature. ${ }^{13,14)}$ The values of $D_{0}$ and $E_{\mathrm{a}}$ for ${ }^{222} \mathrm{Rn}$, which the present authors analyzed using the Arrhenius equation, were found to be similar to those for helium, argon, and neon. ${ }^{19)}$ The $D$ values extrapolated from high temperature to $20^{\circ} \mathrm{C}$ in Fig. 2 are listed in Table 3.

The diffusion might contribute to $E_{\text {Indirect }}$ as well. ${ }^{4)}$ If an energetic recoiling radon atom crosses pores and breaks the surface of an adjacent solid, one might model the formation of a path in the solid. The depth of this path might be compatible to the range, reduced by the fraction of energy already expended. A fraction of embedded radon atoms could move by diffusion to eventually escape from the grain through the path. On the other hand, radiation damages are created by not only recoils but also alpha particles and fission fragments, which can be observed in common minerals, rocks, and soils. Such damages could influence not only $E_{\text {Indirect }}$ but also $E_{\text {Diffusion }}$ if they are interconnected and linked to open surface, as discussed later.

\section{MODELING APPROACHES OF RADON EMANATION}

To our knowledge, a German paper written by FLÜGGE and ZIMENS ${ }^{12)}$ was the first report about radon emanation modeling. Since then, this research theme had not been advanced for a while. The radon emanation modeling study was resumed after radon was recognized as a carcinogen. This section presents an overview of literatures published from 1980s to date.

\section{Recoil-based emanation}

As summarized in Table 4, many studies have theoretically addressed the movement of recoiling radon in solid and pore fluid (air and/or water). ${ }^{10,20-37)}$ The movement and resulting emanation fraction can be computed using information on

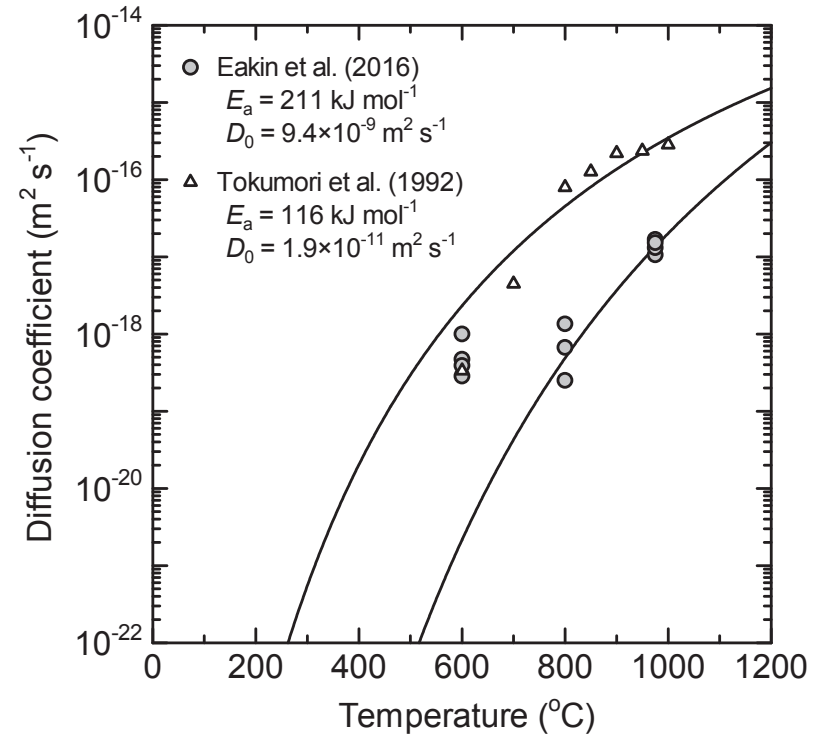

Fig. 2 Diffusion coefficients $(D)$ of ${ }^{222} \mathrm{Rn}$ in minerals as a function of temperature $(t)$. The data were fitted using the Arrhenius equation, $D(t)=D_{0} \exp \left(-\frac{E_{\mathrm{a}}}{R t}\right)$, where $D_{0}$ is the frequency factor, $E_{\mathrm{a}}$ is the activation energy, $R$ is the gas constant. $D$ was obtained in the present study by analyzing original data ${ }^{222} \mathrm{Rn}$ emanation fractions) reported by EAKIN et al. ${ }^{14)}$ and ToKUMORI et al. ${ }^{13)}$ with the following equation: $E_{\text {Diffusion }}=\frac{6}{d}\left(1-E_{\text {Recoil }}\right) \sqrt{\frac{D}{\lambda}}$. Such equation is the asymptotic solution of the diffusion equation based on an assumption that $E$ yielded at ambient temperature corresponded to $E_{\text {Recoil }}$ at any temperature. ${ }^{15,16)}$

recoil ranges in substances or stopping powers as a function of kinetic energy of radon. For simplicity, most researches adopted simple geometric models as displayed in Fig. 3 and assumed uniform radium distribution from solid surface to a certain depth ( $T$, defined in Fig. 4). Furthermore, the embedment of radon has been commonly supposed to occur whenever radon ejected from a grain reaches another solid surface. Referring to previous studies, ${ }^{38,39)}$ only SEMKOW ${ }^{22,23)}$ 
Table 4 Overview of recoil-based radon emanation modeling studies.

\begin{tabular}{cl}
\hline \multicolumn{1}{c}{ Reference } & \multicolumn{1}{c}{ Model (Fig. 3) } \\
\hline FLEISCHER (1983) & Single grain; \\
& Planar pore \\
\hline Bossus (1984) & Planar pore \\
\hline
\end{tabular}

SEMKOW and PAREKH $(1990)^{10)}$ Single grain

Single grain;

SEMKow (1990) 22$) \quad$ Cylindrical pore;

Spherical pore;

Uneven surface

SEMKOW $(1991)^{23)} \quad$ Uneven surface

MorawsKa and

Single grain;

PhILlip (1993) $)^{24)} \quad$ Cylindrical pore

Sun and FurBISH

$(1995)^{25)}$;

SuN $(1995)^{26)}$

Uneven surface

SASAKI et al.

$(2004)^{27)}$

Multiple grains

$\begin{array}{ll} & \\ \text { SASAKI et al. } & \text { Cylindrical pore; } \\ (2004)^{28)} & \text { Planar pore }\end{array}$

$(2004)^{28)} \quad$ Planar pore

SASAKI et al.

$(2005)^{29)}$

Adhering grain

BARILLON et al.

$(2005)^{30)}$

Planar pore

SASAKI et al.

$(2007)^{31)}$

Single grain

SASAKI and GUNJI

$(2008)^{32)}$

Planar pore

ADLER and PERRIER
$(2009)^{33)}$

SAKODA et al. Single grain;

$(2010)^{34,35)} \quad$ Multiple grains

SAKODA and ISHIMORI Multiple grains

$(2014)^{36)}$

StAJIC and NikezIC Single grain;

$(2014)^{37)}$

Multiple grains
Main achievement

$E_{\text {Direct }}$ was calculated using the single-grain or planar-pore model with a given grain- or pore-size distribution. The effect of pore water on the emanation was also presented.

The planar-pore model with infinite pore size (i.e., no embedding effect of the recoiling radon) was addressed to derive a simple formula for $E_{\text {Direct }}$. The calculation of $E_{\text {Diffusion }}$ was also presented.

Successive alpha recoils in uranium series (from ${ }^{238} \mathrm{U}$ to ${ }^{222} \mathrm{Rn}$ ) were simulated with an assumption of the surface or whole-volume distribution of ${ }^{238} \mathrm{U}$ in the single grain, indicating the resulting distribution of radium. $E_{\text {Direct }}$ was then calculated using this radium distribution in the grain. An example of $E_{\text {Direct }}$ calculated as a function of surface porosity was represented for different radiumdistribution conditions. In addition, a brief description was provided about the basis of the multiplegrain model.

First, the analytical solution of $E_{\text {Direct }}$ (in fact, just ejection probabilities from the grain into another solid surface) was provided for a spherical or cylindrical grain or for spherical or cylindrical pore. The effect of surface shape was then examined to discuss radon emanation from a variety of uneven surfaces. Furthermore, other issues were also argued, such as the effects of radon embedding (and its threshold energy), pore water, grain size, and solid edge.

The fractal model of radon emanation from solid surface was developed, and the relation was derived between $E_{\text {Direct }}$ and specific surface area. The result suggested that emanation measurements can be used to determine the fractal dimensions of surface on the scale from tens to hundreds of nanometers.

The single-grain model or the combination model of single grain and cylindrical pore were employed, considering the surface or homogeneous radium distribution in the grain. The combination model was developed to study each contribution of outer and inner surface to $E_{\text {Direct }}$. The result explained the importance of the internal structure (inner pore network), which may be related to porosity, pore size, and pore water. Furthermore, the calculation of $E_{\text {Diffusion }}$ was presented.

The recoil surface area of porous media was determined by quantifying the fractal of the simulated synthetic porous media. The effects of porosity and moisture content were also indicated.

The multiple-grain model, where the number of grains in a single unit was only four in this study, was developed for the first time. The effect of pore water on $E_{\text {Direct }}$ was examined for different grain size ranges. It was found to be significantly given only for grains with less than a few hundred micrometers.

Two pore models (pore size $10 \mathrm{~nm}$; filled with water) were used for the calculation of $E_{\text {Direct }}$ to simulate the so-called nanopore proposed by RAMA and Moore. ${ }^{61)}$ These models could partially explain a role of nanopore, but were not able to yield $E_{\text {Direct }}$ higher than 0.5 , which had sometimes been observed experimentally. The result showed that the cylindrical-planar-pore model gives higher $E_{\text {Direct }}$ than the cylindrical-pore model because of less embedding of radon.

Assuming that very fine grains on the base grain can exclusively include radium and emanate radon, the authors demonstrated the calculated $E_{\text {Direct }}$ value higher than 0.5 , which had sometimes been observed experimentally.

The effects of radium distribution, moisture content, and pore size on $E_{\text {Direct }}$ were illustrated in detail.

The emanation calculations of $E_{\text {Direct }}$ were performed with a cubic-grain model and a spherical-grain model. The spherical-grain model gave higher $E_{\text {Direct }}$ by $35 \%$ for a grain size of $0.1 \mu \mathrm{m}$ and by $15 \%$ for $1.5 \mu \mathrm{m}$.

$E_{\text {Direct }}$ was calculated considering two types of travels of recoiling radon, i.e., straight and zigzag. The $E_{\text {Direct }}$ values were found to be different between the two movements, when pore size was reduced. However, correction because of this difference may be unnecessary for other general emanation models that supposed the straight track.

The complex geometry with randomly packed grains and unsaturated porous media was implemented for the estimation of $E_{\text {Direct }}$.

The effects of grain size, moisture content, and grain-packing structure on $E_{\text {Direct }}$ were shown for different radium-distribution conditions. It was demonstrated that the radon emanation fraction is not necessarily inversely proportional to grain size.

The temperature between -20 and $40^{\circ} \mathrm{C}$ was found to have little impact on $E_{\text {Direct }}$, regardless of grain size.

The application of Monte Carlo simulation to the calculation of $E_{\text {Direct }}$ was validated by comparison with the analytical solution. The effects of grain-packing structure and solid density on the emanation were shown. 
(a) Single grain

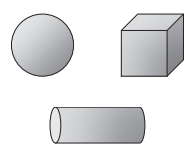

(b) Multiple grains

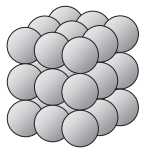

(d) Cylindrical (Spherical) or Planar pore
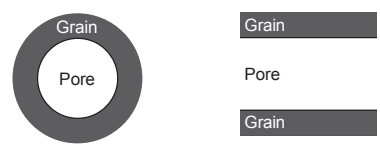

Fig. 3 Grain and pore models used for calculation of radon emanation fraction.

introduced threshold energies for the embedding; the embedding probability ranges from $\sim 10^{-5}$ at $\mathrm{eV}$ energies to $\sim 0.6$ at $3 \mathrm{keV}$, which is equal to 1 at $5 \mathrm{keV}$ and above. The above modeling design can simplify the complicated phenomenon by nature, as seen in Fig. 4.

Radon emanation modeling techniques have been advanced with time; here, we present an overview of these techniques in chronological order. Earlier studies dealt with simple geometric models (cylindrical-, spherical-, or planar-pore models as well as single-grain model, shown in Fig. 3), wherein the ejection probability of radon from a grain was determined as a function of diameter $(d)$ or radium-existing thickness $(T) .{ }^{10,20-22,24)}$ Note that ejection probability is not necessarily equivalent to $E_{\text {Direct }}$ because the concept of embedding effect was not considered in the model. That is, this corresponds with a theoretically maximum value of $E_{\text {Direct }}$ for a given $T$. To evaluate the impact of pore water on $E_{\text {Direct }}$, FLEISCHER ${ }^{20)}$ and SEMKOW ${ }^{22)}$ attempted to incorporate the embedding effect into emanation models. These studies clearly represented that the presence of water enhances emanation, while mathematical solutions of $E_{\text {Direct }}$ were yielded only for two conditions that the pore space is filled by either air or water.

Thereafter, more complex geometric models were implemented, such as the adhering-grain model and uneven-surface model, shown in Fig. 3. ${ }^{22,23,25-33)}$ SemKow, ${ }^{23)}$ Sun, ${ }^{25)}$ and Sun and FurBish ${ }^{26)}$ addressed the emanation computation for simulated solid surfaces with self-similarity to determine surface areas and demonstrate that $E_{\text {Direct }}$ is increased with increasing porosity or moisture content. BARILLON et al. ${ }^{30)}$ worked on the prediction of $E_{\text {Direct }}$ as a function of moisture content by using the planar-pore model into which a pore size distribution was incorporated; they concluded that the calculation successfully illustrated the results of radon emanation fractions measured for uranium mill tailing samples. A series of studies by SASAKI et al. ${ }^{28,29,31,32)}$ were carried out with a variety of motivations and purposes. One of the most notable achievements of their studies was the development of an adhering-grain model that can provide a radon emanation fraction of more than $0.5,{ }^{29)}$ which can be recognized as the expansion of uneven-surface model. When this model is employed, it is necessary to know the ratio of activity (not activity concentration) of radium in adhering fine grains to that in the matrix (base grain). Even with this model, it seems difficult to provide a radon emanation fraction of more than 0.5 , if the matrix accounts for the most part of the total radium activity.

In more recent works, the movement of radon in solid and pore fluid was tracked by Monte Carlo simulation by using information on stopping powers of individual materials of interest as a function of kinetic energy of radon. The simulation can work for any complex geometry of grains and pores, given accurate stopping powers. The present authors $^{34-36)}$ and STAJIC and NiKEZIC ${ }^{37)}$ have computed radon emanation fractions by Monte Carlo simulation as a function of grain size in a certain regular array structure of spherical grains with the same diameter, which is called the multiplegrain model (Fig. 3). To estimate stopping powers of any materials to radon as well as ranges, previous studies have often used a known code, SRIM. ${ }^{7)}$

\section{Diffusion-based emanation}

The general mathematical analysis of the fractional gas loss for other stable inert gases, as explained by FuLDA and LIPPOLT, ${ }^{40)}$ is not applicable to $E_{\text {Diffusion }}$ for radioactive nuclides, including radon. Maraziotis ${ }^{15,16)}$ and RIBEIRO ${ }^{41-43)}$ addressed to derive general solutions for the diffusion of a radionuclide (a)

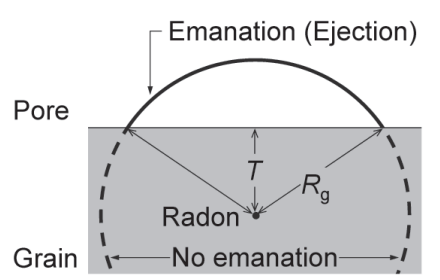

(b)

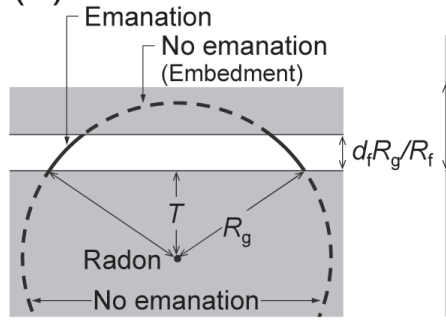

(c)

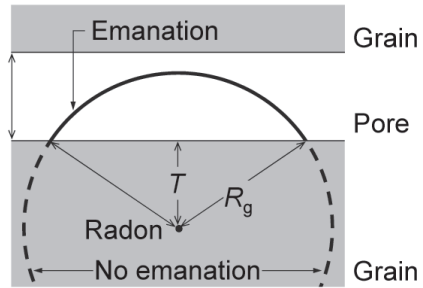

Fig. 4 Simplified designs of radon emanation phenomenon. (a) Single-grain model or planar-pore model without the opposite grain surface. (b) and (c) Reduced size of pore $\left(d_{\mathrm{f}} R_{\mathrm{g}} / R_{\mathrm{f}}\right)$ filled with fluid (either air or water). ${ }^{20,30)}$ The parameter $T$ is the radiumexisting depth from the surface, $d_{\mathrm{f}}$ is the actual pore size, $R_{\mathrm{g}}$ and $R_{\mathrm{f}}$ are the ranges of radon in grain and pore fluid, respectively. The simple pore-size reduction is not possible if the pore is composed of the mixture of air and water. 
produced by the decay of an immobilized parent nuclide in a spherical, homogeneous, and isotropic grain. In particular, the motivation of MARAZIOTIS ${ }^{15,16)}$ was directed to radon, and a simple numerical expression of $E_{\text {Diffusion }}$ for a sphere was presented based on the diffusion theory (Fig. 2). Unlike the recoil-based emanation modeling, the assumption of $T$ has not been introduced to the diffusion-based modeling. The diffusion calculation with such assumption should be performed in the future. At the same time, there is another issue on how to numerically treat the diffusion of radon near solid surface. A unified model of the recoil- and diffusion-based emanation could be interesting and challenging.

\section{ENVIRONMENTAL FACTORS AFFECTING RADON EMANATION FRACTION}

Figures 5-7 show the calculated results of $E_{\text {Direct }}$ as a function of grain size or pore size, assuming various moisture contents or radium thicknesses from solid surfaces. The calculations were based on the single-spherical-grain model, the planar-pore model and the multiple-spherical-grain model (Fig. 3). Only for the single-spherical-grain model, $E_{\text {Diffusion }}$ was also determined with various diffusion coefficients (Fig. 5). Moreover, Fig. 8 shows the ejection probability of radon as a function of $T / R_{\mathrm{g}}$. The following arguments are based on those data.

\section{Radium distribution}

The model calculations revealed that the radium distribution plays a very important role in determining the ejection probability and emanation fraction of radon from the birth grain. Obviously, radium existing at a shallower position can promote radon emanation. This may be consistent with experimental findings about the magnitude of $E$ : soil $\approx$ mill tailing $>$ rock $>$ fly ash $\approx$ mineral. ${ }^{1)}$ Intact minerals are expected to uniformly include radium in solid, leading to lower radon emanation fractions (Table 1). In soils, in contrast, more radium is distributed near solid surface because of factors such as weathering. ${ }^{44-46)}$ Quantitative and precise information on the location of radium atoms in grains would improve emanation modeling, which, however, is quite difficult to be acquired even using cutting-edge techniques.

\section{Moisture content}

A number of experimental studies have examined the effect of pore water on radon emanation. ${ }^{1)}$ The modeling studies with a focus on $E_{\text {Direct }}$ supported the interpretation of empirical data that indicated the elevation of radon emanation with increasing moisture content, as follows. The stopping power of water is much greater than that of air (see the ranges shown in Table 2), which makes recoiling radon very easily settled in pore space before reaching and being embedded into another solid surface. Table 5 indicates the ratios of ${ }^{222} \mathrm{Rn}$ emanation fractions in moist conditions to those in dry conditions. The calculated ratios covered the measured results. This water effect occurs, in theory, under the condition where air-pore size is not large enough to absorb residual energy of ejected recoiling radon. (a) ${ }^{222} \mathrm{Rn}$

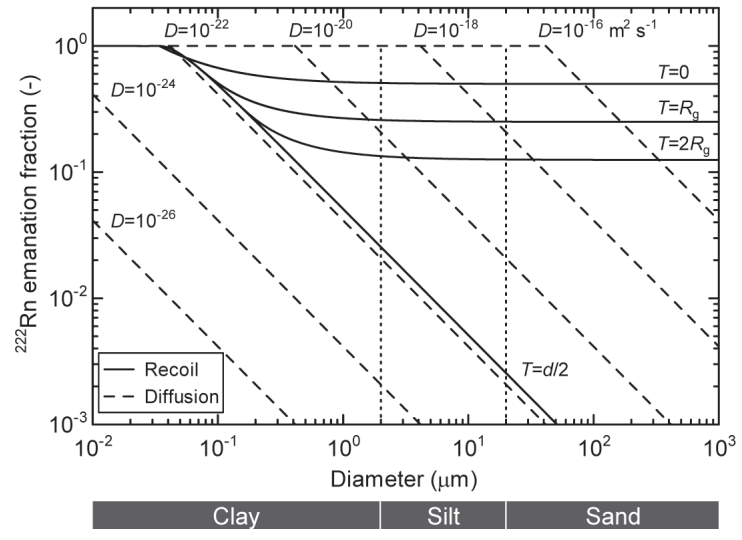

(b) ${ }^{220} \mathrm{Rn}$

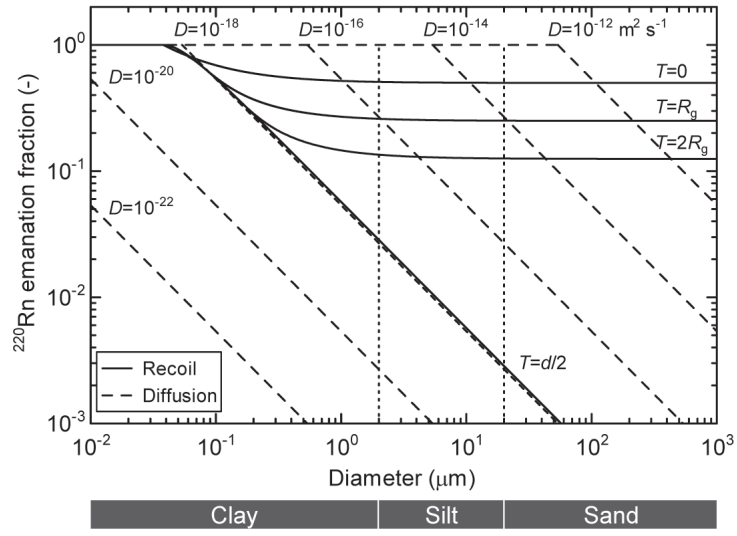

Fig. 5 Radon emanation fractions as a function of diameter (d) in the single-spherical-grain model. The solid curves represent $E_{\text {Direct }}$ for different radium distributions $(T)$, i.e., uniform in or surficial on the grain. $E_{\text {Direct }}$ was calculated using

$E_{\text {Direct }}=\frac{3 R_{\mathrm{g}}}{2 d}-\frac{1}{16}\left(\frac{2 R_{\mathrm{g}}}{d}\right)^{3}$ for $T=d / 2$ (uniform radium) ${ }^{12,20)}$ and Eqs. 4 (a)-(d) of SEMKow ${ }^{22)}$ for the others (surficial radium). The values of $R_{\mathrm{g}}$ for ${ }^{222} \mathrm{Rn}$ and ${ }^{220} \mathrm{Rn}$ were set to be 34 and $38 \mathrm{~nm}$, respectively, assuming a common mineral of quartz $\left(\mathrm{SiO}_{2}\right)$ (Table 1). The dashed curves represent $E_{\text {Diffusion }}$ for various $D\left(\mathrm{~m}^{2} \mathrm{~s}^{-1}\right)$, which was calculated, in the same manner as Fig. 2, using the equation ${ }^{15,16)}$

$E_{\text {Diffusion }}=\frac{6}{d}\left(1-E_{\text {Recoil }}\right) \sqrt{\frac{D}{\lambda}} ; E_{\text {Recoil }}=0$ was assumed.

\section{Grain size}

The modeling studies have also examined the impact of grain size on radon emanation. Both single-grain and multiplegrain models were implemented to simulate more practical grain-packing structures. The two models appeared to result in different trends of $E_{\text {Direct }}$ (Figs. 5 and 7). This difference can be understood from both inter-particle pore size and embedding effect. With the increase in pore size, grain size also increases in the multiple-grain model, ${ }^{34,35)}$ but no concept of inter-particle pore (and its size) is incorporated into the 


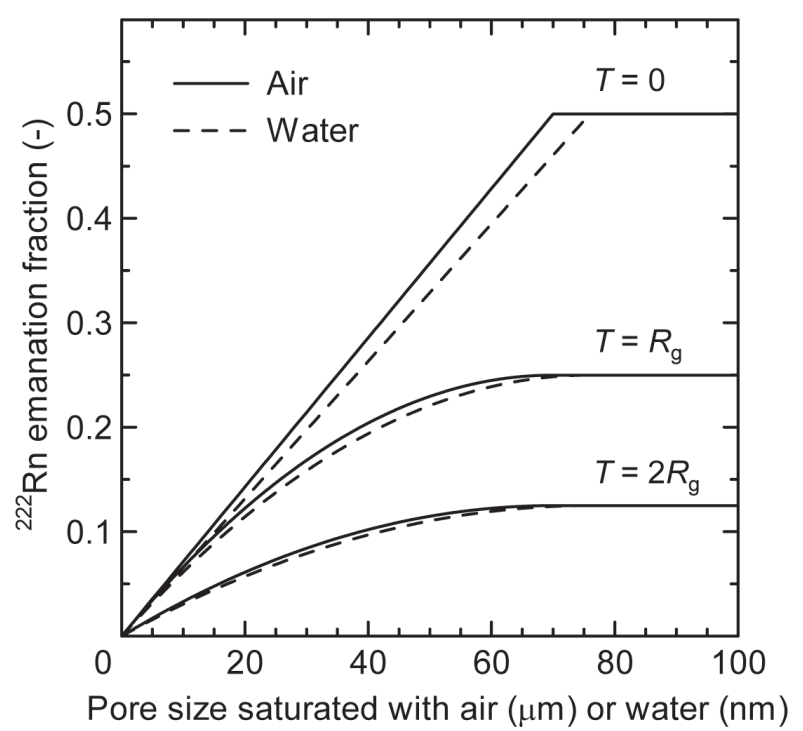

Fig. $6{ }^{222} \mathrm{Rn}$ emanation fraction as a function of pore size in the planar-pore model. The calculation was performed using Eqs. $7-9$ of BARILLON ${ }^{30)}$; pore space is assumed to be completely filled with either air or water. Three kinds of ${ }^{226} \mathrm{Ra}$ thicknesses from the solid surface were set: $T=0, R_{\mathrm{g}}$, and $2 R_{\mathrm{g}}$.

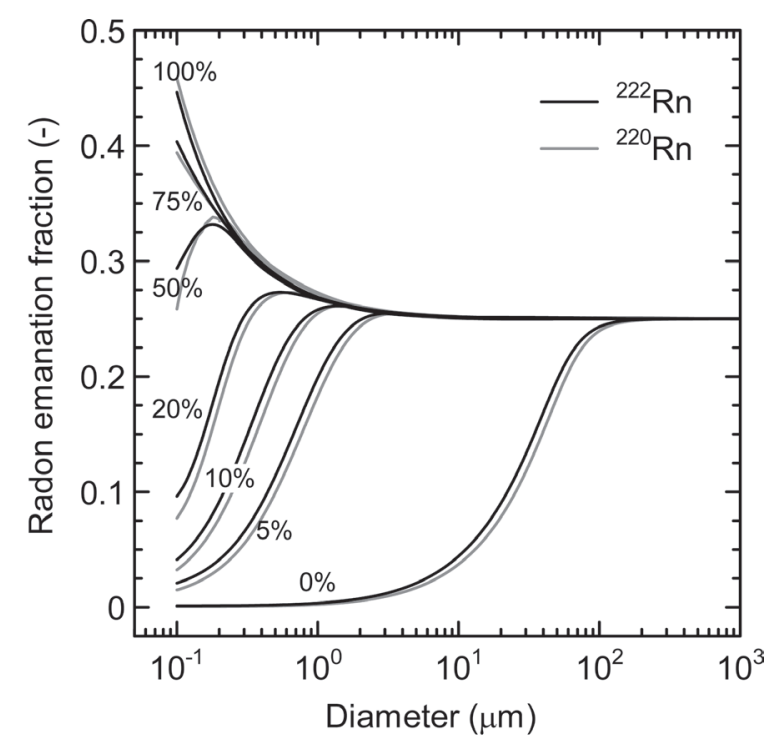

Fig. 7 Radon emanation fraction as a function of diameter in the multiple-spherical-grain model. The computation was carried out by Monte Carlo simulation under various moisture contents in pore $(0-100 \%) .^{35)}$ The radium distribution from the solid surface was assumed to be $T=R_{\mathrm{g}}$.

single-grain model. On the other hand, experimental studies also represented approximately two types of trends of radon emanation fractions, i.e., inversely proportional to or stable independently of grain size. ${ }^{1)}$ The measured trends have been

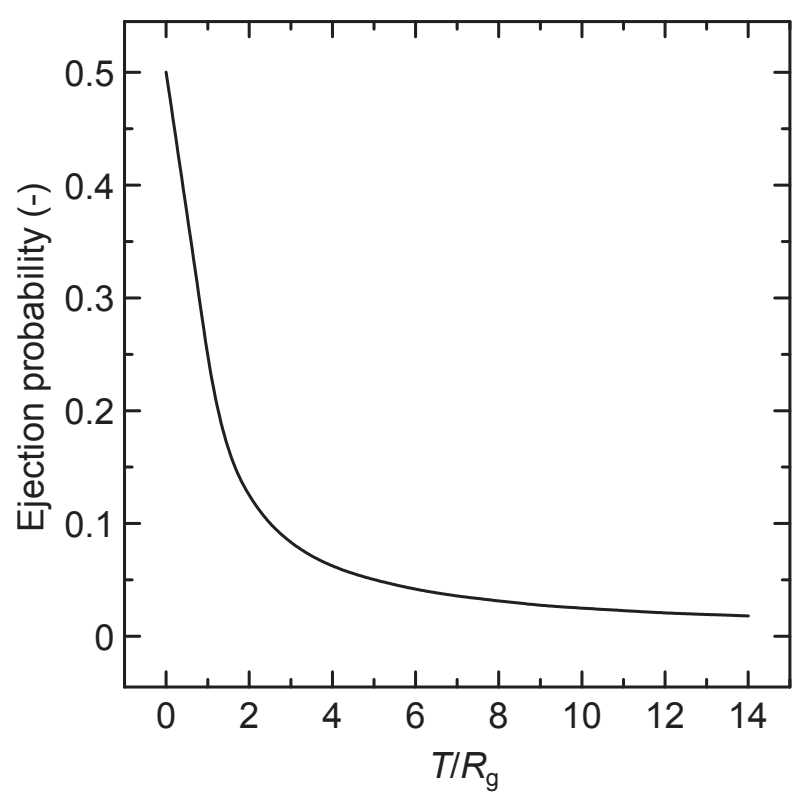

Fig. 8 Ejection probability of radon as a function of the ratio of radium thickness from solid surface to recoil range of radon in solid. Ejection is defined as a radon emanation fraction calculated without embedding effect Fig. 4 (a). That is, this can be given by $\frac{R_{\mathrm{g}}}{4 T}$, which is a possible maximum value of predicted $E_{\text {Direct }}$ and is equivalent to $E_{\text {Direct }}$ in the single-grain model. ${ }^{30,35)}$

Table 5 Impacts of pore water and temperature on ${ }^{222} \mathrm{Rn}$ emanation fraction.

\begin{tabular}{|c|c|c|}
\hline \multirow{2}{*}{ Factor } & \multicolumn{2}{|c|}{ Ratio of ${ }^{222} \mathrm{Rn}$ emanation fractions } \\
\hline & Calculation $\left(E_{\text {Direct }}\right)^{\mathrm{a}}$ & Experiment $^{\mathrm{b}}$ \\
\hline \multirow{3}{*}{ Water (Wet/Dry) } & & \\
\hline & 5.7 & \\
\hline & 1.0 at $d=100$ and 1 & \\
\hline Temperature $\left(40^{\circ} \mathrm{C} / 0^{\circ} \mathrm{C}\right)$ & $0.9-1.0($ at $d=1-1000 \mu \mathrm{m})$ & $1.7 \pm 0.9$ \\
\hline \multicolumn{3}{|c|}{$\begin{array}{l}\text { Water: taken from radon emanation fractions at } 0 \% \text { and } 100 \% \text { in } \\
\text { Fig. } 7 \text {. Temperature: taken from Fig. } 4 \text { of SAKODA and IsHIMORI. }{ }^{36} \\
\text { Water: averaged with data shown in Fig. } 5 \text { of SAKODA et al. }{ }^{1)} \\
\text { Temperature: averaged with data shown in Fig. } 4 \text { of SAKODA et } \\
\text { al. }{ }^{36)}\end{array}$} \\
\hline
\end{tabular}

interpreted with the calculated data on a case-by-case basis, according to specific information and test conditions. Here, it is stated that if the chemical components are not guaranteed to be the same among different grain-size classifications, the grain-size dependence must be carefully examined for a mixture sample as soil. ${ }^{47)}$ In addition, it should be noted that a part of earlier experiments with soil samples might measure not separate (individual) but aggregate grain sizes. The multiple-grain model could be used to express the structure of an aggregate grain.

\section{Temperature}

It can be predicted that if radon emanation tests are 
performed using the same sample in a range of room temperature plus or minus a few tens of degrees Celsius, the result would be almost independent of temperature. This is because diffusion coefficients of radon in solid (as well as stopping powers) would not change in such temperature range. As seen from Table 5, in fact, with the decrease in air density, which is equivalent to the increase in temperature, $E_{\text {Direct }}$ was slightly low because of the embedding effect. ${ }^{36)}$ Nevertheless, several experiments showed that ${ }^{222} \mathrm{Rn}$ emanation fractions were proportionally increased with increasing temperature (summarized by the present authors ${ }^{36}$ ); the emanation fractions at $40^{\circ} \mathrm{C}$ were on average 1.7 times higher than those at $0^{\circ} \mathrm{C}$ (Table 5). Regarding this issue, MesLin et al. ${ }^{48)}$ pointed that the actually measured data in those experiments were apparent radon emanation fractions, since no adsorption correction onto sample grains was carried out. In particular, for dry samples, radon emanation fractions were likely to be underestimated with decreasing temperature. With this viewpoint, the discrepancy between calculated and measured data may be qualitatively understood, and then the methodology for radon emanation tests must be improved.

As temperature was increased by several hundred degrees Celsius, $E_{\text {Diffusion }}$ was elevated by the solid diffusion process (Fig. 2). In the field of geoscience, heating approaches are commonly used to evaluate the diffusivity of noble gases (in particular, helium and argon) for the characterization of mineral samples. ${ }^{19,49)}$ It was sometimes also used for material analysis (called emanation thermal analysis). ${ }^{50)}$ Naturally, high radon emanation fractions $\left(E_{\text {Diffusion }}\right)$ can be observed only during heating. From Fig. 5, it is obvious that for ${ }^{222} \mathrm{Rn}$, $D$ should be at least $10^{-22}$ to $10^{-20} \mathrm{~m}^{2} \mathrm{~s}^{-1}$ for silt and $10^{-20}$ to $10^{-18} \mathrm{~m}^{2} \mathrm{~s}^{-1}$ for sand to yield significant values of $E_{\text {Diffusion }}$ in comparison to $E_{\text {Direct }}$. In the case of ${ }^{220} \mathrm{Rn}$, large $D$ is required because of its short half-life: $10^{-18}$ to $10^{-16} \mathrm{~m}^{2} \mathrm{~s}^{-1}$ for silt and $10^{-16}$ to $10^{-14} \mathrm{~m}^{2} \mathrm{~s}^{-1}$ for sand. This is similar to the results of Bossus ${ }^{21)}$ where $E_{\text {Direct }}$ and $E_{\text {Diffusion }}$ for ${ }^{222} \mathrm{Rn}$ and ${ }^{220} \mathrm{Rn}$ were calculated using a planar-pore model. On the other hand, several studies demonstrated a decrease in ${ }^{222} \mathrm{Rn}$ emanation fractions after heating (up to $1,000^{\circ} \mathrm{C}$ ) and subsequent cooling. ${ }^{51-55)}$ This result may be ascribed to closure of intraand inter-particle pores and annealing of lattice damages. In terms of radiation protection, this finding could be applied to building materials to suppress indoor radon concentration. For this purpose, however, further investigations are necessary to determine the recovery of radon emanation power over time. Its implication was reported earlier. ${ }^{55}$

\section{Inner network in solid}

Mineral grains have been considered to include an inner network of paths that are created by nature, radiation damage, or cracks in crystal lattice. ${ }^{8,56,57)}$ If this network is opened to atmosphere, all three components of radon emanation, i.e., $E_{\text {Direct }}, E_{\text {Indirect, }}$, and $E_{\text {Diffusion, }}$, can be affected. MorawsKA and PHILLIPS ${ }^{24)}$ illustrated a mathematical formulation to calculate $E_{\text {Direct }}$ by considering inner porosities and inner pore diameters in grains, which implied the effect of inner paths. Rock-core deformation tests demonstrated that the collapse of original micro-cracks first declined radon emanation fractions, before they were enhanced by the development connection of isolated micro-cracks. ${ }^{58-60)}$

On the other hand, RAMA and Moore ${ }^{61)}$ postulated the existence of interconnected network, so-called nanopore, to explain commonly observed values of radon emanation fractions in minerals and rocks, which were much higher than expected (for example, see the curve assigned with $T=d / 2$ in Fig. 5). Radon was supposed to recoil into the nanopore and subsequently diffuse to the atmosphere. Later, KRISHNASWAMI and SEIDEMANN ${ }^{62)}$ alternatively advocated that not nanopore but radium concentrated in thin layers on the solid surface, in secondary minerals, or in U-Th accessory minerals is responsible for radon emanation. This finding was based on their observation that the emanation fractions of noble gasses ${ }^{39} \mathrm{Ar}$ and ${ }^{37} \mathrm{Ar}$, created by the reactions ${ }^{39} \mathrm{~K}(\mathrm{n}$, $\mathrm{p})^{39} \mathrm{Ar}$ and ${ }^{40} \mathrm{Ca}(\mathrm{n}, \alpha)^{37} \mathrm{Ar}$ following fast neutron irradiation, were much lower than the ${ }^{222} \mathrm{Rn}$ emanation fractions from mineral and rock samples. The result seemed unreasonable under the assumption that radium is uniformly distributed like other major elements. NAzArofF et al. ${ }^{63)}$ mentioned that these two hypotheses were not mutually exclusive, and both are substantiated by experimental data.

Radiation damage has not yet been incorporated into radon emanation modeling, which could be a factor influencing the migration process in solid. In general, origins of radiation damage in U-Th-rich minerals (e.g., zircon) are alpha-recoiling atoms (mostly major factor), alpha particles, and nuclear fission fragments. In a previous work, the alpha-recoil damage zone in zircon was modeled as a cylinder with a length of $25 \mathrm{~nm}$ and a diameter of $\left.2.5 \mathrm{~nm} .^{8}\right)$ At a low level of radiation damage, alpha-recoil damage zone behaves similar to a sink, lowering overall diffusivity of noble gas with its resulting high tortuosity. As the level of radioactivity rises and an increasing fraction of crystal structure is damaged, the damaged zones begin to be interconnected. When the damaged channels are connected through the solid, the state of percolation is established.

Malczewski and Dziurowicz ${ }^{64)}$ recently measured radon emanation fractions as a function of alpha dose in metamict minerals (oxides, silicates, and phosphates). The ${ }^{222} \mathrm{Rn}$ emanation fractions generally decreased with increasing alpha dose, which could imply the function of radiation damage as a sink. In contrast, the ${ }^{220} \mathrm{Rn}$ emanation fractions were apparently independent of alpha dose. The conclusion referred to the necessity to develop a comprehensive model of ${ }^{222} \mathrm{Rn}$ and ${ }^{220} \mathrm{Rn}$ emanation considering their transport through the inner path network in minerals.

\section{Others}

Emanation fractions of ${ }^{222} \mathrm{Rn}$ from mineral and rock samples in vacuum and ambient pressure (helium atmosphere) were measured. ${ }^{61)}$ The vacuum condition lowered the emanation fractions by $45 \%$ to $79 \%$ in comparison with those in the ambient pressure condition, which might be attributed to the embedding of more recoiling ${ }^{222} \mathrm{Rn}$ in vacuum. The aforementioned models may possibly replicate this result, 
while no computational studies are reported so far.

In contrast, following factors have been studied numerically, but not yet validated experimentally. The multiple-grain models with different porosities were employed in the calculation of $E_{\text {Direct }}$; porosity is $48 \%$ for simple cubic packing and $26 \%$ for face-centered cubic packing. ${ }^{34,35,37)}$ The tightpacking structure with low porosity has small pore sizes on average and thus decreases the emanation fraction only in a certain range of grain sizes (i.e., slope zone before reaching the saturated emanation value at a moisture content of $0 \%$ shown in Fig. 7). Moreover, $E_{\text {Direct }}$ was calculated in relation to solid density ${ }^{37)}$ Eight major minerals were supposed in a wide range of solid densities (e.g., $2.65 \mathrm{~g} \mathrm{~cm}^{-3}$ for quartz and $4.65 \mathrm{~g} \mathrm{~cm}^{-3}$ for zircon). The result was evident, as expected, to depend on ejection probabilities of radon from the birth grain, because of the difference of recoil ranges in the samples. The range was short in heavy minerals, resulting in small $E_{\text {Direct }}$. The density could be one of the factors affecting radon emanation to some extent, but its importance cannot be experimentally validated because different minerals have own physical and chemical characteristics (other than density) that would strongly influence radon emanation.

\section{CONCLUSIONS}

Many radon emanation measurements have been conducted in terms of radiation protection, with most emanation modeling studies focusing on $E_{\text {Direct }}$, which was considered to play a dominant role in the natural environment. A series of calculation results of $E_{\text {Direct }}$ provided interpretations for existing experimental results (e.g., water effect), or implications on the impacts of environmental factors (e.g., radium distribution), which were difficult to be controlled as parameters in emanation measurements. A model that can simultaneously account for $E_{\text {Indirect }}$ and $E_{\text {Diffusion }}$ as well as $E_{\text {Direct }}$ is desired to be developed in the future, considering the transport of ${ }^{222} \mathrm{Rn}$ and ${ }^{220} \mathrm{Rn}$ through the inner path network in minerals. In this new model, radium distribution would still be a key factor governing radon emanation, and thereby more experimental evaluation should be conducted for the sake of more realistic modeling.

\section{REFERENCES}

1) A. SAKoda, Y. Ishimori and K. YAMAOKA; A comprehensive review of radon emanation measurements for mineral, rock, soil, mill tailing and fly ash, Appl. Radiat. Isot., 69, 1422-1435 (2011).

2) International Atomic Energy Agency (IAEA); Measurement and calculation of radon releases from NORM residues, Technical Reports Series No. 474 (2013).

3) W. W. NaZaroff; Radon transport from soil to air, Rev. Geophys., 30, 137-160 (1992).

4) A. B. TANNER; Radon migration in the ground: A supplementary review, T. F. GESELl and W. M. Lowder (eds.) "Natural Radiation Environment III", p. 5-56 (1980), Conf-780422, National Technical Information Service, U. S. Department of Commerce, Virginia.

5) T. SASAKI and Y. GUNJI; Radon emanation phenomena:
Previous studies and future outlook, Trans. At. Energy Soc. Jpn., 5, 374-381 (2006) (in Japanese with English abstract).

6) International Commission on Radiological Protection (ICRP); Nuclear decay data for dosimetric calculations, ICRP Publication 107, Ann. ICRP, 38 (2008).

7) J. F. Ziegler, J. P. Biersack and U. Littmark; "The Stopping and Range of Ions in Solids", (1985), Pergamon Press, New York.

8) R. A. Ketcham, W. R. Guenthner and P. W. Reiners; Geometric analysis of radiation damage connectivity in zircon, and its implications for helium diffusion, $\mathrm{Am}$. Miner., 98, 350-360 (2013).

9) R. JONCKheERE and K. Gögen; A Monte-Carlo calculation of the size distribution of latent alpha-recoil tracks, Nucl. Instr. Meth. Phys. Res. B, 183, 347-357 (2001).

10) T. M. Semkow and P. P. Parekh; The role of radium distribution and property in radon emanation from solids, Geophys. Res. Lett., 17, 837-840 (1990).

11) V. A. Leach, K. H. LoKan and L. J. Martin; A study of radiation parameters in an open-pit mine, Health Phys., 43, 363-375 (1982).

12) S. FLÜGGE and K. E. ZimENS; Die bestimmung von korngrössen und diffusionskonstanten aus dem emaniervermögen, Z. Phys. Chem. B, 42, 179-220 (1939) (in German).

13) K. ToKUmori; Radon exhalation from potash feldspar, M. Shimo and T. Tsujimoto (eds.) "Environmental Radon", Proceedings of the '91 Radon Symposium held at Kumatori, p. 116-123 (1992), Electron Science Institute, Osaka, (in Japanese with English abstract).

14) M. Eakin, S. J. Brownlee, M. Baskaran and L. Barbero; Mechanisms of radon loss from zircon: Microstructural controls on emanation and diffusion, Geochim. Cosmochim. Acta, 184, 212-226 (2016).

15) E. A. Maraziotis; Effects of intraparticle porosity on the radon emanation coefficient, Environ. Sci. Technol., 30, 2441-2448 (1996).

16) E. A. Maraziotis; Theoretical evaluation of the ${ }^{222} \mathrm{Rn}$ emanation coefficient for coal fly ash, Health Phys., 52, 297-302 (1987).

17) T. P. BARton and P. L. Ziemer; The effects of particle size and moisture content on the emanation of Rn from coal ash, Health Phys., 50, 581-588 (1986).

18) D. R. Kalkwarf, P. O. Jackson and J. C. Kutt; Emanation coefficients for Rn in sized coal fly ash, Health Phys., 48, 429-436 (1985).

19) E. BAXTER; Diffusion of noble gases in minerals, Rev. Mineral. Geochem., 72, 509-557 (2010).

20) R. L. Fleischer; Theory of alpha recoil effects on radon release and isotopic disequilibrium, Geochim. Cosmochim. Acta, 47, 779-784 (1983).

21) D. A. W. Bossus; Emanating power and specific surface area, Radiat. Prot. Dosim., 7, 73-76 (1984).

22) T. M. Semкow; Recoil-emanation theory applied to radon release from mineral grains, Geochim. Cosmochim. Acta, 54, 425-440 (1990).

23) T. M. SEMKow; Fractal model of radon emanation from 
solids, Phys. Rev. Lett., 66, 3012-3015 (1991).

24) L. Morawska and C. R. Phillips; Dependence of the radon emanation coefficient on radium distribution and internal structure of the material, Geochim. Cosmochim. Acta, 57, 1783-1197 (1993).

25) H. Sun; Monte Carlo simulation of radon emanation from dry building materials, Health Phys., 68, 553-560 (1995).

26) H. Sun and D. J. Furbish; Moisture content effect on radon emanation in porous media, J. Contam. Hydrol., 18, 239-255 (1995).

27) T. SASAKI, Y. GunJI and T. OKuda; Mathematical modeling of radon emanation, J. Nucl. Sci. Technol., 41, 142-151 (2004).

28) T. Sasaki, Y. Gunj and T. Okuda; Radon emanation dependence on grain configuration, J. Nucl. Sci. Technol., 41, 993-1002 (2004).

29) T. Sasaki, Y. GunJI and T. OKuda; Theoretical study of high radon emanation, J. Nucl. Sci. Technol., 42, 242-249 (2005).

30) R. Barillon, A. Özgümüs and A. Chambaudet; Direct recoil radon emanation from crystalline phases. Influence of moisture content, Geochim. Cosmochim. Acta, 69, 2735-2744 (2005).

31) T. SASAKI, Y. GUNJI and T. OKUDA; Theoretical estimation of radon emanation coefficients for $\mathrm{UO}_{2}$ particles deposited on surfaces of uranium-bearing wastes, $\mathrm{J}$. Nucl. Sci. Technol., 44, 774-778 (2007).

32) T. SASAKI and Y. GunJI; Radon emanation phenomena: A probabilistic basis to estimate radon emanation coefficients based on its zigzag travel, J. Nucl. Sci. Technol., 45, 932941 (2008).

33) P. M. Adler and F. Perrier; Radon emanation in partially saturated porous media, Transp. Porous Med., 78, 149159 (2009).

34) A. Sakoda, K. Hanamoto, Y. Ishimori, T. Kataoka, A. KaWABE and K. YAMAOKA; First model of the effect of grain size on radon emanation, Appl. Radiat. Isot., 68, 1169-1172 (2010).

35) A. Sakoda, Y. Ishimori, K. Hanamoto, T. Kataoka, A. Kawabe and K. Yamaoka; Experimental and modeling studies of grain size and moisture content effects on radon emanation, Radiat. Meas., 45, 204-210 (2010).

36) A. SAKoda and Y. Ishimori; Calculation of temperature dependence of radon emanation due to alpha recoil, $J$. Radioanal. Nucl. Chem., 299, 2013-2017 (2014).

37) J. M. STAJIC and D. NikeZIC; Theoretical calculation of radon emanation fraction, Nucl. Instr. Meth. Phys. Res. B, 336, 19-25 (2014).

38) E. V. Kornelsen; The ionic entrapment and thermal desorption of inert gases in tungsten for kinetic energies of $40 \mathrm{eV}$ to $5 \mathrm{keV}$, Can. J. Phys., 42, 364-381 (1964).

39) F. Brown and J. A. Davies; The effect of energy and integrated flux on the retention and range of inert gas ions injected at keV energies in metals, Can. J. Phys., 41, 844-857 (1963).

40) C. Fulda and H. J. Lippolt; Diffusion coefficients of noble gases in natural minerals: An apparent experimental time dependence caused by domain size spectra, Math. Geol., 32, 31-47 (2000).

41) F. B. Ribeiro; A general solution in the cylindrical coordinates system for the diffusion of a radionuclide in homogeneous and isotropic solids, Radiat. Meas., 30, 153 (1999).

42) F. B. Ribeiro; Simultaneous diffusion of isotopes from a radioactive series in homogeneous and isotropic solids, Radiat. Meas., 29, 9-18 (1998).

43) F. B. Ribeiro; A general solution for the diffusion of a radioactive isotope in homogeneous and isotopic solids, Radiat. Meas., 26, 747-750 (1996).

44) F. Girault; F. Perrier, M. Moreira, B. Zanda, P Rochette and Y. Teitler; Effective radium-226 concentration in meteorites, Geochim. Cosmochim. Acta, 208, 198-219 (2017).

45) D. Breitner, T. Turtiainen, H. Arvela, P. Vesterbacka, B. Johanson, M. Lehtonen, K-H. Hellmuth and C. Szabó; Multidisciplinary analysis of Finnish esker sediment in radon source identification, Sci. Total Environ., 405, 129139 (2008).

46) A. Baeza, M. Del Rio, A. Jimenez, C. Miro and J. Paniagua; Influence of geology and soil particle size on the surface-area/volume activity ratio for natural radionuclides, J. Radioanal. Nucl. Chem., 189, 289-299 (1995).

47) A. Sakoda, Y. Nishiyama, K. Hanamoto, Y. Ishimori, Y. Yamamoto, T. Kataoka, A. Kamabe and. K. Yamaoka; Differences of natural radioactivity and radon emanation fraction among constituent minerals of rock or soil, Appl. Radiat. Isot., 68, 1180-1184 (2010).

48) P. Y. Meslin, J. C. Sabroux, S. Bassot and E. CHASSEFIÈRE; Experimental study of radon production and transport in an analogue of the Martian regolith, Geochim. Cosmochim. Acta, 75, 2256-2270 (2011).

49) T. M. Harrison and P. K. Zeitler; Fundamentals of noble gas thermochronometry, Rev. Mineral. Geochem., 58, 123-149 (2005).

50) V. Balek, L. A. Pérez-Maqueda, J. Poyato, Z. Černý, V. Ramírez-Valle, I. M. Buntseva and J. L. PérezRoDRíGUEZ; Effect of grinding on thermal reactivity of ceramic clay minerals, J. Therm. Anal. Calorim., 88, 87-91 (2007).

51) K. Krupp, M. Baskaran and S. J. Brownlee; Radon emanation coefficients of several minerals: How they vary with physical and mineralogical properties, Am. Miner., 102, 1375-1383 (2017).

52) Z. Sas, J. Szántó, J. Kovács, J. Somlai and T. Kovács; Influencing effect of heat-treatment on radon emanation and exhalation characteristic of red mud, J. Environ. Radioact., 148, 27-32 (2015).

53) V. Jobbágy, J. Somlai, J. Kovács, G. Szeiler and T. KovÁcs; Dependence of radon emanation of red mud bauxite processing wastes on heat treatment, J. Hazard. Mater., 172, 1258-1263 (2009).

54) E. Garver and M. Baskaran; Effects of heating on the emanation rates of radon-222 from a suite of natural 
minerals, Appl. Radiat. Isot., 61, 1477-1485 (2004).

55) V. L. Shashkin and M. I. Prutkina; Mechanism underlying the emanation of radioactive ores and minerals, Atom. Energy, 29, 724-726 (1970).

56) W. R. Guenthner, P. W. Reiners, R. A. Ketcham, L. Nasdala and G. Giester; Helium diffusion in natural zircon: radiation damage, anisotropy, and the interpretation of zircon (U-Th)/He thermochronology, Am. J. Sci., 313, 145-198 (2013).

57) R. F. Holub and B. T. BRady; The effect of stress on radon emanation from rock, J. Geophys. Res., 86, 1776-1784 (1981).

58) F. Girault, A. Schubnel and É. Pili; Transient radon signals driven by fluid pressure pulse, micro-crack closure, and failure during granite deformation experiments, Earth Planet. Sci. Lett., 75, 2256-2270 (2011).

59) K. Koike, T. Yoshinaga, K. Suetsugu, K. Kashiwaya and H. Asaue; Controls on radon emission from granite as evidenced by compression testing to failure, Geophys. $J$. Int., 203, 428-436 (2015).

60) P. Tuccimei, S. Mollo, M. Soligo, P. Scarlato and M. CAstelluccio; Real-time setup to measure radon emission during rock deformation: implications for geochemical surveillance, Geosci. Instrum. Method. Data Syst., 4, 111-119 (2015).

61) Rama and W. S. Moore; Mechanism of transport of U-Th series radioisotopes from solids into ground water, Geochim. Cosmochim. Acta, 48, 395-399 (1984).
62) S. Krishnaswami and D. E. Seidemann; Comparative study of ${ }^{222} \mathrm{Rn},{ }^{40} \mathrm{Ar},{ }^{39} \mathrm{Ar}$ and ${ }^{37} \mathrm{Ar}$ leakage from rocks and minerals: Implications for the role of nanopores in gas transport through natural silicates, Geochim. Cosmochim. Acta, 52, 655-658 (1988).

63) W. W. Nazaroff, B. A. Moed and R. G. Sextro; Soil as a source of indoor radon: generation, migration, and entry, W. W. Nazaroff and A. V. Nero (eds.) "Radon and Its Decay Products in Indoor Air", p. 57-112 (1988), John Wiley \& Sons, New York.

64) D. Malczewski and M. Dziurowicz; ${ }^{222} \mathrm{Rn}$ and ${ }^{220} \mathrm{Rn}$ emanations as a function of the absorbed $\alpha$-doses from select metamict minerals, Am. Miner., 100, 1378-1385 (2015).

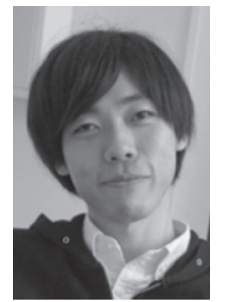

Akihiro SAKoda

Akihiro SAKODA received a $\mathrm{PhD}$ in Health Sciences from Okayama University in 2009. He has been working for the Japan Atomic Energy Agency since 2010. In 2014, he was also a guest scientist at Helmholtz Zentrum München, Germany. The main field of research is environmental radioactivity; in particular, the evaluation of behavior of radon in the environment, and the dose assessment in a variety of radon exposure routes. 